\section{Reinforced Glass-ceramics: Parametric Inspection of Three- Dimensional Wear and Volumetric Loss after Chewing Simulation}

João Paulo Mendes Tribst ${ }^{1,2} \mathbb{D}$, Larissa Marcia Marques Alves ${ }^{1} \mathbb{D}$, Amanda Maria de Oliveira Dal Piva ${ }^{1,2}$, Renata Marques de Melo ${ }^{1} \mathbb{D}^{\circ}$, Alexandre Luiz Souto Borges ${ }^{1}{ }^{\mathbb{D}}$, Tarcísio José Arruda Paes-Junior ${ }^{1} \mathbb{B}$, Marco Antonio Bottino ${ }^{1}$ (1)

\begin{abstract}
The aim of this study was to investigate the three-dimensional wear, volumetric loss and surface roughness after chewing simulation of two glass ceramics. Lithium disilicate (LD, Emax CAD, Ivoclar) and Zirconia reinforced lithium silicate (ZLS, Vita Suprinity, Vita Zhanfabrick) discs ( $n=20 / g$ ) were scanned to obtain stereolithography (STL) files for each sample. All discs were submitted to chewing simulation with sliding configuration (30 $\mathrm{N}, 300,000$ cycles, $6 \mathrm{~mm}$ and $1.7 \mathrm{~Hz}$ ) with steatite as antagonist. The samples were then scanned again and the volume loss and the deepest defect depth was measured using the superimposed file from the baseline using three-dimensional digital parametric inspection software (GOM Inspect, Braunschweig, Germany). Surface roughness (Ra and Rz) was analyzed with a contact profilometer. Data were analyzed by one-way ANOVA and Tukey test $(\alpha=0.5 \%)$. ANOVA showed significant differences among the groups. Considering the ceramic volume loss, wear depth defect length and Rz roughness, LD $(-22.09 \pm 5.57 \%$; $0.80 \pm 0.06 \mu \mathrm{m} ; 3.08 \pm 1.02 \mu \mathrm{m})$ showed higher mean values than ZLS $(-15.67 \pm 4.51 \%$; $0.56 \pm 0.09 \mu \mathrm{m} ; 1.51 \pm 0.90 \mu \mathrm{m})$. Ra mean values were similar for both materials $(\mathrm{p}=0.064)$. All discs exhibited slight surface scratches along with the sliding direction with pitted wear patterns, while large cracks were observed on wear traces. These same areas can be identified in blue, overlapping the STL files before and after chewing simulation in inspection software. The linear reduction generated by sliding contact shows a graph with a similar wear pattern shape. ZLS was more resistant to wear than LD, with less volume loss and shallower surface defects.
\end{abstract}

'Department of Dental Materials and Prosthodontics, UNESP Universidade Estadual Paulista, São José dos Campos, SP, Brazil ${ }^{2}$ Department of Dental Materials Science, ACTA - Academic Centre for Dentistry Amsterdam Universiteit van Amsterdam and Vrije Universiteit, LA Amsterdam, Noord-Holland, The Netherlands

Correspondence: João Paulo Mendes Tribst, Av. Eng. Francisco José Longo, $\mathrm{n}^{\circ} 777,12245-000$ São José dos Campos, SP, Brasil. Tel: +55-12-98126-4653. e-mail: amanda.piva@ict.unesp.br / Amanda Maria de Oiveira Dal Piva, Gustav Mahlerlaan, 1081, \#3004 LA Amsterdam, Noord-Holland, The Netherlands. Tel: +31-6-85051348. e-mail: amodalpiva@gmail.com

Key Words: ceramics, wear simulation, volume loss

\section{Introduction}

The incorporation of crystalline particles inside glasses matrices enables dental ceramics to reach high fracture resistance due to smaller crack propagations without compromising the final aesthetics (1). Among the main ceramics used in dentistry, lithium disilicate ceramics are noteworthy for their extensive indication: veneers, inlays, onlays (1), monolithic crowns $(1,2)$, copings, fixed prostheses (1), hybrid abutments (3) and endocrowns (4). Another ceramic with a similar function is zirconia reinforced lithium silicate, possessing reinforcement crystals in the monosilicate phase instead of disilicate. In addition, zirconia particles were incorporated inside the glass matrix to promote better mechanical properties when subjected to masticatory forces (5).

Despite the difference in composition, the literature is not as concise regarding the differences between lithium disilicate and zirconia reinforced lithium silicate materials. There are reports of superior strength in zirconia reinforced lithium silicate $(6,7)$ and reports of superior strength in lithium disilicate (8), or even similar mechanical behavior between them (2). Therefore, other criteria should also be considered to help the clinician in choosing which material to use. Likewise, long-term investigations should be performed to evaluate the behavior of these materials.

A methodology that simulates a longitudinal evaluation is the wear resistance of restorative materials $(9,10)$. A material with good resistance to wear will not modify the patient's vertical dimension, nor the restoration shape and its consequent aesthetics. The wear resistance of lithium disilicate is reported to be adequate as it does not decrease the restoration volume during chewing, nor cause excessive wear on the antagonist dentition $(10,11)$. Several studies report that this material can experience wear differently in the oral environment due to its individual mechanical properties, and micro- and macrostructural composition (11-13).

Since zirconia reinforced lithium silicate is a ceramic possessing different reinforcing crystals other than lithium disilicate, it is important to ascertain whether they have similar indications if both materials are capable of maintaining their integrity after simulated wear. Based on this concern, some studies have evaluated the wear caused by the natural dentition in zirconia reinforced 
lithium silicate ceramics $(10,14)$, and comparing these results with the results for lithium disilicate ceramic wear. Since the data obtained by a direct comparison are important, it is necessary to verify the performance of these materials throughout the surface. Moreover, the parametric inspection of the scanning files before and after the wear simulation can enable verifying the volume loss and the depth of the generated defects. In the proposed method, the specimen is verified as a whole and not just a single area, as in the case of the analysis by profilometry or surface roughness (9).

Thus, the goal of this study was to compare the volume loss and the depth of wear generated after wear simulation in two dental ceramics using a three-dimensional parametric inspection and scanning electron microscopy. The null hypothesis was that there would be no difference between the ceramics under the evaluated criteria.

\section{Material and Methods}

\section{Samples Preparation}

Two CAD/CAM (Computer Aided Design/Computer Aided Manufacture) ceramic materials were selected: lithium disilicate glass ceramics [(IPS e.max CAD, Ivoclar ¿ Vivadent, Schaan, Liechtenstein) - subgroup LD] and zirconia reinforced lithium silicate [(Vita Suprinity, VITA Zahnfabrik H. Rauter GmbH \& Co., BadSäckingen, Germany) - subgroup ZLS]. Two blocks of each material were rounded in an automatic orbital sander (Ecomet 250 ; Buehler, Lake Bluff, IL, USA) using water sandpaper with grain size \#600. Next, the rollers were cut using a precision cutting machine (Isomet 1000, Buehler) into 2-mm thick disc specimens under constant water irrigation to fabricate the disc specimens $(n=20, n=40)$. All specimens were finished with an applied force of $33 \mathrm{~N}$ at a speed of $100 \mathrm{rpm}$ for 5 min with different grits of silicon carbide grinding papers $(120,240,320,600,1200 \mathrm{grit})$ and polishing with specific rubber points in order to assure surface smoothness and parallelism before the wear simulation (10). Afterwards, all samples were cleaned with isopropyl alcohol in an ultrasonic bath ( $5 \mathrm{~min}$ ) and crystallized in a furnace according to the manufacturer's instructions. For lithium disilicate, stand-by temperature of $403^{\circ} \mathrm{C}$ followed by 6 min closing time; first firing temperature (T1) of $820^{\circ} \mathrm{C}$ - heating rate of $90{ }^{\circ} \mathrm{C} /$ $\mathrm{min}$ and held for $10 \mathrm{~min}$; second firing temperature (T2) of $840{ }^{\circ} \mathrm{C}$ - heating rate of $30^{\circ} \mathrm{C} / \mathrm{min}$ and held for $7 \mathrm{~min}$. For ZLS, a stand-by temperature of $400{ }^{\circ} \mathrm{C}$ followed by 8 min closing time; firing temperature of $840{ }^{\circ} \mathrm{C}$ - heating rate of $55^{\circ} \mathrm{C} / \mathrm{min}$ and held for $8 \mathrm{~min}$.

\section{Wear Simulation}

Each sample was scanned (CEREC AC Omnicam, Sirona, São Paulo, SP, Brazil) before the wear simulation, and the stereolithography (STL) file was stored in a CAD system (Romexis, 4.5.0.R, Planmeca). Each three-dimensional (3D) file was numbered according to the representative sample for further evaluation. The scan accuracy was 2.1 micrometers according to the manufacturer. All specimens were then individually embedded in autopolymerizing acrylic resin cylinder, leaving the top of each disc uncovered. Thus, the samples were submitted to the wear simulator (Biocylce V2, Biopdi, São Carlos, SP, Brazil) with $2 \mathrm{~mm}$ steatite pistons (magnesium silicate, Ceramica Chiarotti, Jaguariúna, SP, Brazil), which served as analogue to dental enamel antagonist (15-17). The wear simulator operates by applying a vertical load on the specimen, sliding horizontally, and then repeating the cycle (16). The parameters for this test were as follows: load of 30 $\mathrm{N}$, frequency of $1.7 \mathrm{~Hz}$, sliding distance of $6 \mathrm{~mm}$ and 300,000 cycles at room temperature and in distilled water (16). Water was used to keep the antagonists wet, remove worn particles, and simulate the wet environment of the oral cavity.

\section{Parametric Wear and Volume Loss Analysis}

The volume loss from each disc was measured using an intraoral scanner (CEREC AC Omnicam, Sirona, São Paulo, SP, Brazil). The 3D STL files of the wear facets were collected (Fig. 1A) and superimposed (Fig. 1B) from the baseline using a 3D digital parametric inspection software (GOM Inspect, Braunschweig, Germany) (9). This software generated a colorimetric map of each specimen and then aligned the models to detect the geometric changes that illustrate the wear caused by the antagonist (Fig. 1C). Next, the linear reduction of the discs was also detected by aligning the center of STL file of the disc before and after wear by two-dimensionally comparing them (18). The data report indicates the ceramic volume loss (\%) and defect depth in micrometers (Fig. 2). Data were analyzed by descriptive statistics, one-way analysis of variance and Tukey test with 5\% significance.

\section{Surface Roughness}

After wear test, the specimens' surface roughness was evaluated with a contact profilometer (SJ-410, Mitutoyo, Tokyo, Japan). Three parallel readings per specimen were performed and Ra and Rz parameters were measured with Gaussian Filter and cut-off wavelength value of $0.8 \mathrm{~mm}$. The parameters' means of each specimen was then obtained (10). Data were analyzed by descriptive statistics, one-way analysis of variance and Tukey test, all with 5\% significance.

\section{Scanning Electron Microscopy (SEM)}

Two representative samples after wear simulation were inspected using SEM (Inspect S50, FEI, Czech Republic). The 

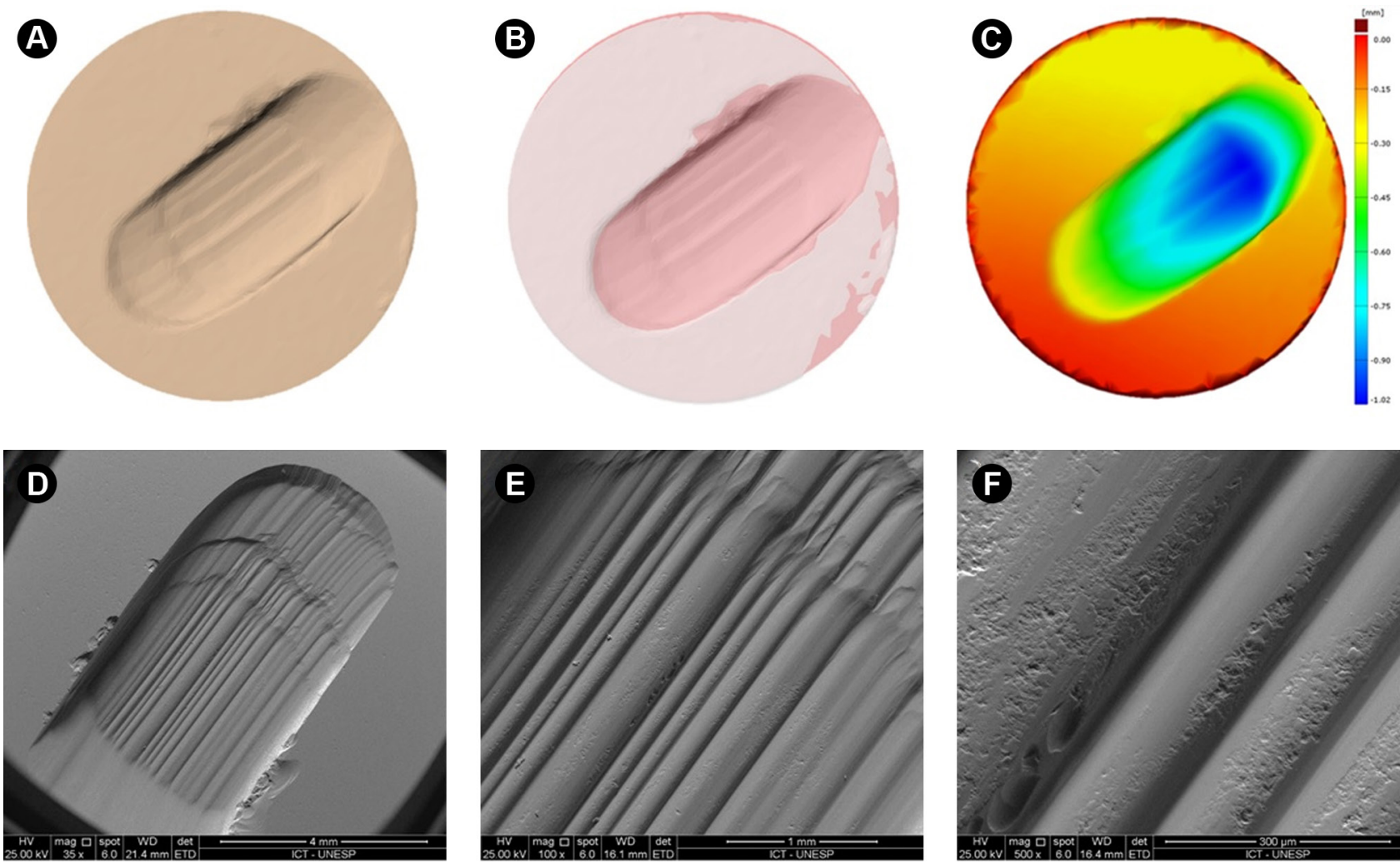

Figure 1. A-F: Wear parametric analysis and top surface morphology observation. A: Stereolithography file of one representative sample after wear simulation. B: Superimposition of the sample before and after wear simulation. C: Colorimetric map to detect the geometric changes that illustrate the wear caused by the antagonist. SEM micrographic images of the surface defect at D (35x), E (100x) and F (500x).
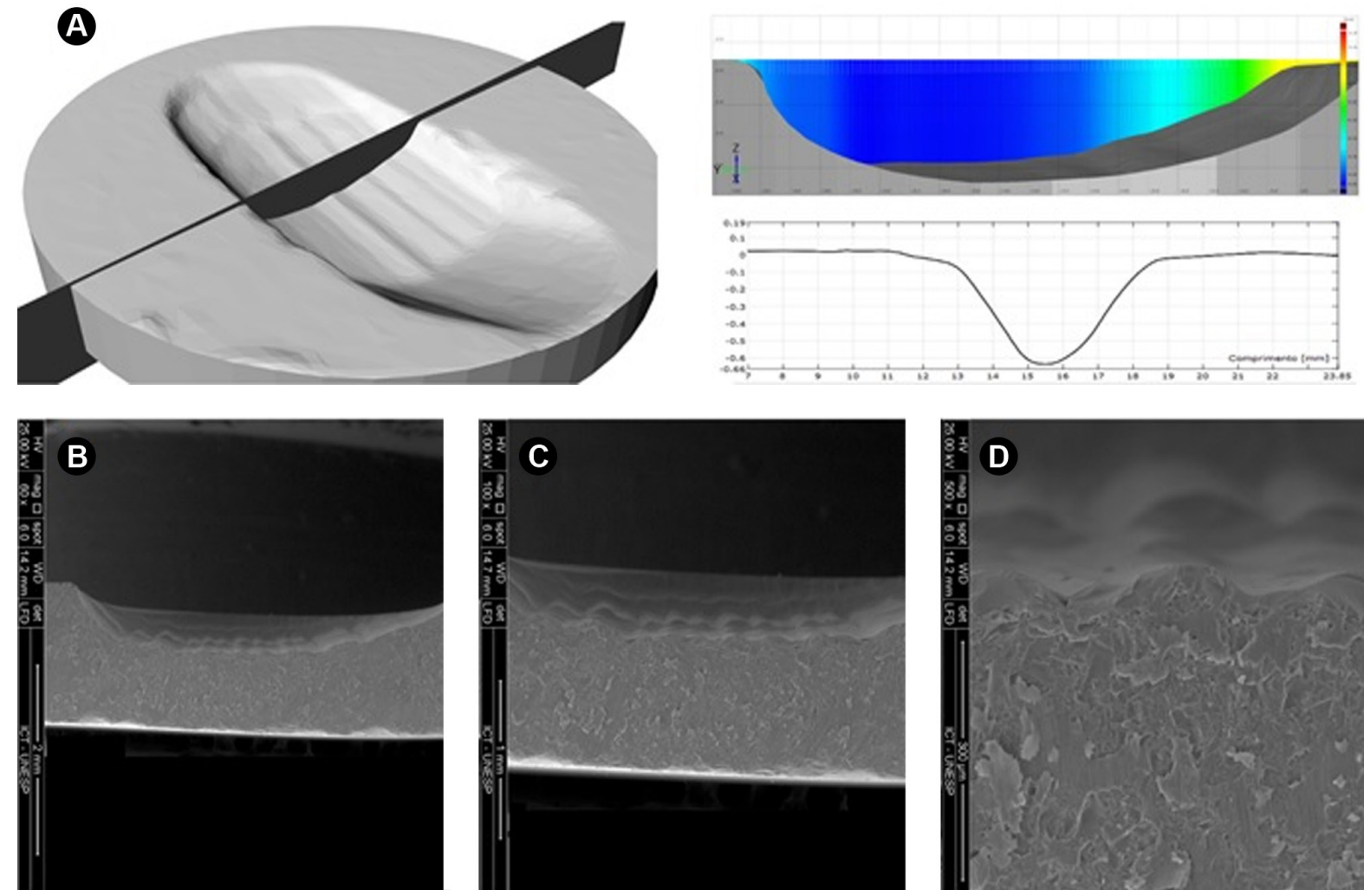

Figure 2. A: Illustration of the analyzed plane and its observation using the analysis software. B,C,D: Sagittal analysis of the surface defect. SEM micrographic images of the defects in the same view at B (60x), C (100x) and D (500x). 
samples were perpendicularly cut in two parts for direct comparison with the 3D model. The specimens were sputter coated with gold for $130 \mathrm{~s}$ at $15 \mathrm{~mA}$, creating a 30-nmthick layer and examined under different standard SEM magnifications operated at $20 \mathrm{KV}$ using secondary electron detection by a single operator (10).

\section{Results}

\section{Parametric Wear and Volume Loss Analysis}

A boxplot of volume loss and wear depth data are summarized in Figure 3. Descriptive statistics are shown in Table 1. One-way ANOVA showed statistically significant differences among the groups considering the ceramic volume loss and wear depth defect length (Table 2).

\section{Surface Roughness}

One-way ANOVA showed that Ra, average surface roughness, $(p=0.064)$ was similar between ZLS $(0.25 \pm 0.18$ $\mu \mathrm{m})$ and $L D(0.29 \pm 0.23 \mu \mathrm{m})$. While $R z$, the high parameter, $(p=0.001)$ showed that LD $(3.08 \pm 1.02)$ presented higher mean value than ZLS $(1.51 \pm 0.90)$.

\begin{tabular}{|c|c|c|}
\hline \multicolumn{3}{|c|}{$\begin{array}{l}\text { Table } 1 \text {. Volume loss (in \%), wear depth defect length }(\mu \mathrm{m}) \text {, minimum } \\
\text { and maximum values for lithium disilicate (LD) and zirconia reinforced } \\
\text { lithium silicate (ZLS) }\end{array}$} \\
\hline & $\mathrm{LD}$ & ZLS \\
\hline Volume loss (\%) & $-22.09 \pm 5.57$ & $-15.67 \pm 4.51$ \\
\hline Minimum (\%) & -14.49 & -10.90 \\
\hline Maximum (\%) & -32.26 & -25.93 \\
\hline Wear deep defect length $(\mu \mathrm{m})$ & $0.80 \pm 0.06$ & $0.56 \pm 0.09$ \\
\hline Minimum $(\mu \mathrm{m})$ & 0.72 & 0.56 \\
\hline Maximum ( $\mu \mathrm{m})$ & 0.95 & 0.74 \\
\hline
\end{tabular}

According to SEM images, all discs exhibited slight surface scratches along the sliding direction with pitted wear patterns, and large cracks were also observed on wear traces (Fig. 1D-F). These same areas can be identified in blue, overlapping the STL files before and after chewing simulation in inspection software (Fig. 2A). The linear reduction generated by sliding contact shows a graph with a similar wear pattern shape (Fig. 2B-D).

\section{Discussion}

The results herein demonstrated statistically significant differences among the ceramics volume loss and wear depth defect length. Therefore, the null hypothesis was rejected. Sliding fatigue is widely used in laboratory tests to evaluate the wear resistance of restorative materials (18). Despite the limitations in movement, it is a reproducible method that provides a stressed material with superficial microfatigue. Previous studies evaluating the wear resistance of dental ceramics used cuspal tips of molars

Table 2. One-way Analysis of Variance results of volume loss and wear depth defect length according to the ceramic material

\begin{tabular}{lccccc}
\hline Volume Loss & & & & & \\
\hline Source & DF & Adj SS & Adj MS & F value & p value \\
Ceramic material & 1 & 206 & 206 & 8.00 & 0.011 \\
Error & 18 & 464 & 25 & & \\
Total & 59 & 670 & & & \\
\hline Wear Deep & & & & & \\
Defect Length & & & & & \\
\hline Source & DF & Adj SS & Adj MS & F value & P value \\
Ceramic material & 1 & 0.5923 & 0.592285 & 85.83 & 0.000 \\
Error & 38 & 0.2622 & 0.006901 & & \\
Total & 39 & 0.8545 & & & \\
\hline
\end{tabular}
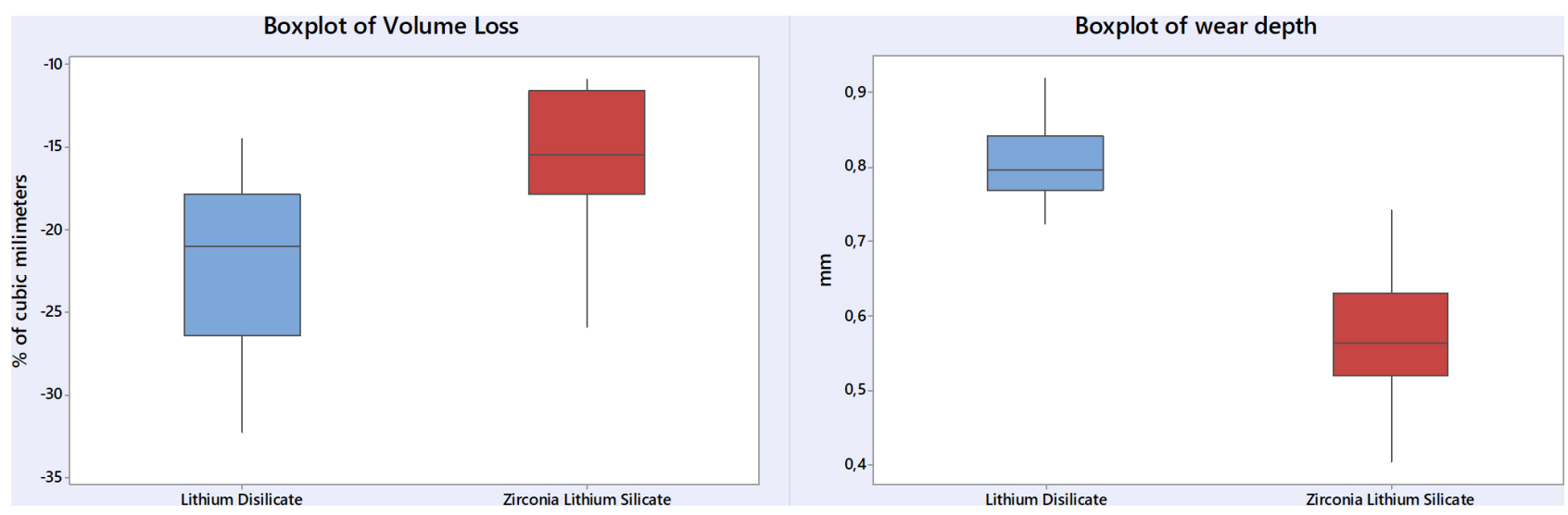

Figure 3: Boxplot graphs of the amount of volume loss (in \%) and wear depth defect length (in $\mathrm{mm}$ ) according to the ceramic material. 
extracted as antagonists during the cyclic test (19-22). The use of an analogue in steatite was previously validated in the literature as a substitute for dental enamel because it has similar mechanical characteristics (17), enables better specimen standardization, facilitates reproducibility of the study and also geometry control. Thus, steatite was the material of choice for promoting in vitro wear.

The method used herein was reported in studies that verified the final effect on the geometry of a specimen after mechanical fatigue. Zandparsa et al. (18) evaluated the dental enamel wear against different restorative materials, verifying the volume loss and the defect depth. The authors did not find a statistically significant difference for the studied effects and still found discrepancies between the verification of volume loss and defect depth generated at the tips of the worn teeth. In contrast, the present study found a significant difference for both analysis parameters between the tested materials. It is worth mentioning that the accuracy of the scanner used is very important for this methodology, because low wear values which are undetectable by the 3D file can suggest a false positive result. Therefore, a scanner with higher accuracy than that previously reported (18) was used herein.

The 3D measurement of total wear was performed in previous studies using CAD software $(23,24)$. The innovation in the present study and the study of Zandparsa et al. (18) is the possibility of measuring the wear depth, as well as the evidence of worn areas in a parametric manner by a computational overlap of previous files and post fatigue through specific software. The overlap in drawing software can be empirical and inaccurate.

Lithium disilicate was more susceptible to wear with greater loss of volume and generated defect depth compared to the zirconia reinforced lithium silicate under the same conditions. The elastic modulus of the restorations is also a factor correlated with the stress concentration on the surface in response to the applied occlusal forces. As the ZLS presents a smaller elastic modulus than the LD, previous studies report lower stress concentration in its structure. Moreover, Dal Piva et al. (2) define that this material has a lower risk of mechanical failure than the $L D$, which corroborates the findings of the present study. The direct comparison of the wear resistance between LD and ZLS was previously performed (11) through evaluating the 3D model in CAD software. Our findings corroborate the findings that ZLS presented lower volume loss (23.6 $\pm 7.6 \%)$ in comparison

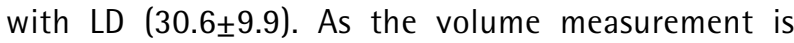
independent of the spatial position of the geometric model, the use of CAD software for this is perfectly applicable. However, a specific overlap parameter must be used in order to verify the defect depth generated by the wear, such as those found in 3D inspection software. Thus, the authors did not find statistical differences for the defect depth among the ceramics, even though a difference in the lost volume was found. Therefore, the present study deviates in showing that the ceramic that lost more volume presented deeper defects (11). On the other hand, Lawson et al. (12) compared the wear of several dental materials submitted to sliding chewing simulation in a similar device to that used in this manuscript. Although LD had approximately $33 \%$ more volume loss than ZLS, the authors found no statistical difference between the wear generated for both materials. The authors also report lower elastic modulus and higher hardness for the ZLS, which would justify the smaller volume loss in comparison to the LD. The SEM figure herein (Figs. 1 and 2) corroborates that previous investigation (12), which showed the same defect pattern generated on the discs' surface after chewing simulation. It is important to emphasize that this study used 20 specimens and only performed a statistical comparison between two materials instead of $n=10$ and a comparison of 8 substrates as in the discussed study. Contact profilometry was also applied as a measurement technique for simulated in vitro wear. (9) The authors compared ZLS with two polymer infiltrated ceramics and found that the substance loss on the crowns were found to be on a comparable level for glass ceramic in the resin interpenetrating matrix and ZLS.

Regarding surface roughness, Matzinger et al. (11) did not found difference between ZLS and LD using Ra parameter after chewing simulation. Therefore, the results corroborates with those findings for the parameter of average surface defects. When using another roughness parameter, analyzing the difference between the highest peak and deepest vale $(\mathrm{Rz})$ it was possible to point difference between both materials. Rz results corroborates with wear test finding, where the material less strength to resist to the volume loss (LD) was also more susceptible to show higher $R z$ values.

Ludovichetti et al. (15) used two-body wear test with ACTA wear machine for 200,000 cycles and determined the wear rate with a surface profilometer. The authors did not found statistically difference between ZLS and LD for wear against bovine enamel. This may have happened due to the absence of cyclic compressive load of this type of test, being the main difference with the method herein.

According to the paper of Elsaka et al. (5), ZLS present a homogeneous fine crystalline structure while LD shows a structure with needle-shaped fine-grained crystals embedded in a glassy matrix. Since the microstructure is influenced by the relation between crystalline phase and glassy matrix, any surface or subsurface defect can aggravate wear by fatigue process. Thus, reinforcing the importance a smooth surface to maintain the integrity and texture of the ceramic (25). This can justify the difference 
in roughness between both tested ceramics, allowing more shear between LD and the antagonist, consequently increasing the wear and volume loss. In spite of the limitations of this study, it is possible to conclude that the zirconia reinforced lithium silicate was more wear resistant than lithium disilicate, with less volume loss throughout the wear simulation and exhibited shallower surface defects.

\section{Resumo}

0 objetivo deste estudo foi investigar o desgaste tridimensional, perda volumétrica e rugosidade após a simulação de mastigação de dois materiais vitro-cerâmicos. Discos de dissilicato de lítio (LD, Emax CAD, Ivoclar) e silicato de lítio reforçado com zircônia (ZLS, Vita Suprinity, Vita Zhanfabrick) ( $\mathrm{n=20/g}$ ) foram confeccionados e digitalizados para obtenção de arquivos de estereolitografia (STL) de cada amostra. Todos os discos foram submetidos à simulação de mastigação com configuração deslizante ( $30 \mathrm{~N}, 300.000$ ciclos, $6 \mathrm{~mm}$ e 1,7 Hz) com esteatita como antagonista. As amostras foram escaneadas novamente e a perda de volume e o defeito mais profundo foram medidos usando o arquivo sobreposto da linha de base através de um software de inspeção paramétrica digital e tridimensional (GOM Inspect, Braunschweig, Alemanha). A rugosidade superficial ( $R a$ e $\mathrm{Rz}$ ) foi avaliada através de rugosímetro de contato. Os resultados foram analisados por ANOVA 1 -fator e teste Tukey $(\alpha=0,5 \%)$. ANOVA mostrou diferenças significantes entre os grupos. Considerando a perda de volume cerâmico, comprimento do defeito e rugosidade $\mathrm{Rz}$, LD $(-22,09 \pm 5,57 \% ; 0,80 \pm 0,06 \mu \mathrm{m} ; 3,08 \pm 1.02 \mu \mathrm{m})$ apresentou valores médios superiores a ZLS $(-15,67 \pm 4,51 \% ; 0,56 \pm 0,09 \mu \mathrm{m} ; 1.51 \pm 0.90 \mu \mathrm{m})$. $\vec{\Xi}$ Todos os discos exibiram pequenos arranhões na superfície conforme a direção de deslizamento com padrões de desgaste, enquanto grandes ranhuras foram observadas nos traços de desgaste. Essas mesmas áreas podem ser identificadas em azul, sobrepondo os arquivos STL antes e depois da simulação de mastigação no software de inspeção. A redução Q. linear gerada pelo contato deslizante mostra um gráfico com uma forma $\rightarrow$ de padrão de desgaste semelhante. ZLS foi mais resistente ao desgaste do que $L D$, com menor perda de volume e menores defeitos superficiais.

\section{References}

1. Pieger S, Salman A, Bidra AS. Clinical outcomes of lithium disilicate single crowns and partial fixed dental prostheses: a systematic review. J Prosthet Dent 2014;112:22-30.

2. Dal Piva AMO, Tribst JPM, Borges ALS, Souza ROAE, Bottino MA. CAD-FEA modeling and analysis of different full crown monolithic restorations. Dent Mater 2018;S0109-5641:30026-30035.

3. Tribst JPM, Dal Piva AMO, Borges ALS, Bottino MA. Influence of crown and hybrid abutment ceramic materials on the stress distribution of implant-supported prosthesis. Rev Odontol UNESP 2018;47:149-154.

4. Tribst JPM, Dal Piva AMO, Madruga CFL, Valera MC, Borges ALS, Bresciani $E_{1}$ et al. Endocrown restorations: Influence of dental remnant and restorative material on stress distribution. Dent Mater 2018;S01095641:31303-31309.

5. Elsaka SE, Elnaghy AM. Mechanical properties of zirconia reinforced lithium silicate glass-ceramic. Dent Mater 2016;32:908-914.

6. Zimmermann $M$, Egli $G$, Zaruba $M$, Mehl A. Influence of material thickness on fractural strength of CAD/CAM fabricated ceramic crowns. Dent Mater J 2017:29;36:778-783.

7. Hamza TA, Sherif RM. Fracture resistance of monolithic glass- ceramics versus bilayered zirconia-based restorations. J Prosthodont 2019;28:e259-e264.

8. Sieper K, Wille S, Kern M. Fracture strength of lithium disilicate crowns compared to polymer-infiltrated ceramic-network and zirconia reinforced lithium silicate crowns. J Mech Behav Biomed Mater 2017;74:342-348.

9. Naumova EA, Schneider S, Arnold WH, Piwowarczyk A. Wear Behavior of Ceramic CAD/CAM Crowns and Natural Antagonists. Materials (Basel) 2017;10:E244.

10. Madruga CFL, Bueno MG, Dal Piva AMO, Prochnow C, Pereira GKR, Bottino MA, et al. Sequential usage of diamond bur for CAD/CAM milling: Effect on the roughness, topography and fatigue strength of lithium disilicate glass ceramic. J Mech Behav Biomed Mater 2019;91:326-334.

11. Matzinger $M$, Hahnel $S$, Preis $V$, Rosentritt $M$. Polishing effects and wear performance of chairside CAD/CAM materials. Clin Oral Investig 2019;23:725-737.

12. Lawson NC, Bansal R, Burgess JO. Wear, strength, modulus and hardness of CAD/CAM thyrestorative materials. Dent Mater 2016;32:e275-e283.

13. Oh WS, Delong $R$, Anusavice KJ. Factors affecting enamel and ceramic wear: a literature review. J Prosthet Dent 2002;87:451-459.

14. Heintze SD, Cavalleri A, Forjanic M, Zellweger G, Rousson V. Wear of ceramic and antagonist--a systematic evaluation of influencing factors in vitro. Dent Mater 2008;24:433-439.

15. Ludovichetti FS, Trindade FZ, Werner A, Kleverlaan CJ, Fonseca RG. Wear resistance and abrasiveness of CAD-CAM monolithic materials. J Prosthet Dent 2018;120:318:e1-318.e8.

16. Stawarczyk B, Özcan M, Schmutz F, Trottmann A, Roos M, Hämmerle $\mathrm{CH}$. Two-body wear of monolithic, veneered and glazed zirconia and their corresponding enamel antagonists. Acta Odontol Scand 2013;71:102-112.

17. Preis V, Grumser K, Schneider-Feyrer S, Behr M, Rosentritt M. Cycledependent in vitro wear performance of dental ceramics after clinical surface treatments. J Mech Behav Biomed Mater 2016;53:4958.

18. Zandparsa R, El Huni RM, Hirayama H, Johnson MI. Effect of different dental ceramic systems on the wear of human enamel: An in vitro study. J Prosthet Dent 2016;115:230-237.

19. Mitov G, Heintze SD, Walz S, Woll K, Muecklich F, Pospiech P. Wear behavior of dental Y-TZP ceramic against natural enamel after different finishing procedures. Dent Mater 2012;28:909-918.

20. Sripetchdanond J, Leevailoj C. Wear of human enamel opposing monolithic zirconia, glass ceramic, and composite resin: an in vitro study. J Prosthet Dent 2014;112:1141-1150.

21. Amer $R$, Kürklü $D$, Johnston W. Effect of simulated mastication on the surface roughness of three ceramic systems. J Prosthet Dent 2015; 114:260-265.

22. Stawarczyk B, Frevert $K$, Ender A, Roos M, Sener B, Wimmer T. Comparison of four monolithic zirconia materials with conventional ones: Contrast ratio, grain size, four-point flexural strength and twobody wear. J Mech Behav Biomed Mater 2016;59:128-138.

23. Choi JW, Song EJ, Shin JH, Jeong TS, Huh JB. In vitro investigation of wear of CAD/CAM polymeric materials against primary Teeth. Materials (Basel) 2017;10:e1410.

24. Zierden K, Acar J, Rehmann P, Wöstmann B. Wear and fracture strength of new ceramic resins for chairside milling. Int J Prosthodont2 018;31:74-76.

25. Fathy SM, Swain MV. In-vitro wear of natural tooth surface opposed with zirconia reinforced lithium silicate glass ceramic after accelerated ageing. Dent Mater 2018;34:551-559. 